\title{
Prevalence of peripheral arterial disease and associated factors in people with type 2 diabetes
}

\author{
Prevalência e fatores associados \\ à doença arterial periférica em \\ pessoas com diabetes tipo 2
}

Pedro José da Silva Filho (D) ${ }^{1}$

Elaine Cristina Martinez Teodoro (1) ${ }^{2}$

Elaine Cristina Alves Pereira (D) ${ }^{2}$

Vania Cristina dos Reis Miranda (D) ${ }^{2 *}$

${ }^{1}$ Pontifícia Universidade Católica de Campinas (PUC-Campinas), Campinas, SP, Brazil

${ }^{2}$ Centro Universitário FUNVIC (UniFUNVIC), Pindamonhangaba, SP, Brazil

Date of first submission: December 16, 2020

Last received: August 16, 2021

Accepted: August 16, 2021

Associate editor: Ana Paula Cunha Loureiro

*Correspondence: vcrmiranda2@gmail.com

\begin{abstract}
Introduction: The high rate of diabetes mellitus index (DM), along with the increase in cardiovascular compromise that DM favors, and the scarcity of epidemiological data regarding the prevalence of peripheral arterial disease (PAD) in this population, make it important to study risk factors associated with the development of PAD in the population with type 2 diabetes mellitus (DM2). Objective: To estimate the prevalence of PAD together with the associated factors in a sample of patients with DM2, treated in the Family Health Strategies (FHS) program, in the municipality of Pindamonhangaba, SP. Methods: Quantitative research in a cross-sectional study of 38 individuals who were diagnosed with DM2, between 40 and 77 years old, selected by convenience sampling and treated in the family health program in two different districts of the municipality. The method consisted of the evaluation of personal and anthropometric data, anamnesis and physical examination including the ankle-brachial index (ABI). Results: PAD was present in $21.1 \%$ (95\% Cl: 16.9 to 25.8) of the investigated population. Risk factors observed were age range of 51 to 69 years (75\%), overweight (50\%), systemic arterial hypertension (SAH) (100\%), smoking (62.5\%) and physical inactivity (87.5\%). Conclusion: The prevalence of PAD was more than a fifth of those diagnosed with DM2, and the most prevalent associated risk factors were $\mathrm{SAH}$, physical inactivity, smoking and overweight with and without PAD.
\end{abstract}

Keywords: Diabetes mellitus. Peripheral arterial disease. Risk factors. Prevalence. 


\section{Resumo}

Introdução: $O$ alto índice de acometimento de indivíduos com diabetes mellitus (DM), somado ao aumento de comprometimentos cardiovasculares que a patologia favorece e a escassez de dados epidemiológicos referentes à prevalência de doença arterial periférica (DAP) nesta população, torna-se importante o estudo dos fatores de risco associados ao desenvolvimento desta condição na população com diabetes mellitus tipo 2 (DM2). Objetivo: Estimar a prevalência de DAP em conjunto com os fatores associados em uma amostra de pacientes com DM2, tratados em Estratégias de Saúde da Família (ESF) no município de Pindamonhangaba, SP. Métodos: Pesquisa quantitativa em um estudo transversal composto por 38 indivíduos diagnosticados com DM2, com idade entre 40 e 77 anos, selecionados por conveniência e atendidos no programa de saúde da família de dois bairros distintos do município. O método constituiu-se na avaliação com dados pessoais, antropométricos, anamnese e exame físico com a avaliação do índice tornozelo-braquial (ITB). Resultados: A DAP esteve presente em 21,1\% (IC 95\%: 16,9 a $25,8)$ da população investigada. Como fatores de risco foram observados faixa etária de 51 a 69 anos (75\%), sobrepeso (50\%), hipertensão arterial sistêmica (HAS) (100\%), tabagismo (62,5\%) e sedentarismo (87,5\%). Conclusão: A prevalência de $D A P$ atingiu mais de um quinto dos indivíduos diagnosticados com DM2 e os fatores de risco associados mais presentes foram HAS, sedentarismo, tabagismo e sobrepeso nos indivíduos com e sem DAP.

Palavras-chave: Diabetes mellitus. Doença arterial periférica. Prevalência. Fatores de risco.

\section{Introduction}

Peripheral arterial disease (PAD) is a dysfunction that limits blood flow to the lower limbs. ${ }^{1-3}$ The ESC Guidelines on the Diagnosis and Treatment of Peripheral Arterial Diseases, together with the European Society for Vascular Surgery (ESVS), showed that in developed countries, individuals manifest the disease beginning at 50 years of age and with an increase in its incidence after 65 years old, reaching about $20 \%$ after 80. Developing countries have an incidence of 9.9 per 1000 people per year, with a risk of 7.8 for men and 12.4 for women. ${ }^{4}$
The most common cause of PAD is the atherosclerosis process, ${ }^{1-3}$ which involves several cellular and molecular responses interacting with different highly specific cellular factors. ${ }^{5}$ These processes occur more rapidly because of hyperglycemia, through oxidative reactions, increased free radicals and increased oxidative stress. ${ }^{5-7}$ The formation and deposition of advanced glycation end products (AGEs) directly cause extracellular matrix abnormalities and lipoprotein modifications. In addition, other interactions lead to the generation of reactive oxygen species (ROS), which favor the transcription of inflammatory genes in the vascular wall. 5,7,8 Thus, these oxidative stresses are also aggravated in obesity. ${ }^{7}$

The process of atherosclerosis and consequently the onset of PAD occur more frequently, earlier and more severely in individuals with diabetes mellitus (DM). 9,10 Therefore, PAD accounts for high rates of amputation and death, demonstrating a greater risk of morbidity and mortality from cardiovascular conditions. ${ }^{1}$ The most common of these is acute coronary syndrome (ACS), for which individuals with diabetes plus PAD have a worse prognosis compared to individuals with diabetes and no PAD. $^{11}$

Normally, individuals affected by PAD are asymptomatic even in moderate stages. ${ }^{12}$ Thus, these silent changes involving PAD can be assessed using the ankle-brachial index (ABI), a non-invasive, effective and practical method. ${ }^{12,13}$ Considered the gold standard, $A B I$ has high sensitivity and specificity for detecting PAD, with the disease being symptomatic or asymptomatic. ${ }^{14}$

Due to the high rate of individuals diagnosed with DM, the increase in cardiovascular compromise that DM favors and the scarcity of epidemiological data regarding the prevalence of PAD, added to the associated factors in individuals affected by type 2 diabetes mellitus (DM2), the aim of the present study was to determine the prevalence of PAD together with the associated risk factors in a sample of patients with DM2 treated in the Family Health Strategies (FHS) program, in the city of Pindamonhangaba, SP, Brazil.

\section{Methods}

The study included individuals with DM2 who used the FHS in two neighborhoods in Pindamonhangaba, and who were evaluated according to the availability of 
health facilities. All users were diagnosed and treated by the Unified Health System (SUS), with regard to DM2 and other conditions reported and verified in the medical records. The inclusion criteria were: DM2 present, individuals who were followed up in the FHS, individuals without a previous diagnosis of PAD. The exclusion criteria were: use of insulin, individuals with cognitive impairment and hearing, visual or communication difficulties.

\section{Study sampling}

The study individuals were recruited by consecutive convenience sampling, according to the patients diagnosed with DM2 and registered in the FHS, who met the inclusion criteria of this study, thus characterizing a non-probabilistic sample.

The sample was determined on the basis of data from HIPERDIA (hypertension and diabetes) from the TABNET health information system in Pindamonhangaba from 2002 to April 2013. An expected proportion of $16 \%$ was considered, ${ }^{15}$ which used $\mathrm{ABI}$ as a diagnostic method, with a margin of error of $10 \%$ and a $90 \%$ confidence interval $(\mathrm{Cl})$, which resulted in a sample of 38 individuals.

The project was submitted for evaluation by the Research Ethics Committee through Plataforma Brasil and approved under assessment number 2.196.892, guaranteeing the privacy of volunteers, who all signed an informed consent form.

After the assessment of $A B I$, the individuals were divided into two groups to compare some data: normal $\mathrm{ABI}$ and altered $\mathrm{ABI}$.

Sociodemographic, anthropometric profile and risk factors

For the sociodemographic profile, the volunteers underwent an interview with questions about their personal information (name, age, sex, race, marital status and level of schooling) and socioeconomic level (if they received any type of benefits from the government).

The individuals were asked about their current state of health through anamnesis consisting of the investigation of associated conditions (systemic arterial hypertension - $\mathrm{SAH}$; dyslipidemias; and previous diagnosis of PAD) reported by the patients themselves who were undergoing treatment, which was confirmed through analysis of medical records; family history (cardiovascular disease - CVD; DM; SAH and dyslipidemia) and lifestyle habits (sedentary lifestyle, characterized by physical activity less than 150 minutes per week; current or past smoking; and current or past drinking). Vital signs collected at rest were: heart rate (HR), systolic blood pressure (SBP) and diastolic blood pressure (DBP).

To obtain the anthropometric data, height in meters was measured using a tape measure, weight in kilograms, using a $110 \mathrm{CH}$ Welmy model scale, and body mass index (BMI) from these data. For BMI analysis, individuals were classified as normal weight (18.5 to $24.9 \mathrm{~kg} / \mathrm{m}^{2}$ ), overweight (25.0 to $\left.29.9 \mathrm{~kg} / \mathrm{m}^{2}\right)$, grade 1 obesity $(30.0$ to $\left.34.9 \mathrm{~kg} / \mathrm{m}^{2}\right)$, grade 2 obesity $\left(35.0\right.$ to $39.9 \mathrm{~kg} / \mathrm{m}^{2}$ ) and grade 3 obesity ( $\geq 40.0 \mathrm{~kg} / \mathrm{m}^{2}$ ), according to the Brazilian Association for the Study of Obesity and Metabolic Syndrome (ABESO). ${ }^{16}$

Waist circumference (WC) was measured using a measuring tape, at the midpoint between the iliac crest and the last rib, on the bare skin. For females, WC of 80 to $88 \mathrm{~cm}$ was considered as moderate cardiovascular risk and $>88 \mathrm{~cm}$ as high risk, with the ideal value being $<80$ $\mathrm{cm}$. For males, the value considered ideal was $<94 \mathrm{~cm}$, with 94 to $102 \mathrm{~cm}$ indicating moderate cardiovascular risk and $>102 \mathrm{~cm}$ high risk. ${ }^{17}$

\section{Measurement of $A B I$}

To measure $\mathrm{ABI}$, the ESVS recommendations ${ }^{4}$ were followed using a MedMega 610 vascular Doppler device and a 10 to $12 \mathrm{~cm}$ sphygmomanometer cuff, with a 5-minute rest in the supine position before the measurement. The systolic pressures of the brachial arteries in the upper limbs and the dorsal arteries of the foot and posterior tibial arteries in the lower limbs were measured. The measurement was performed by only one of the researchers, who was trained to do so.

The calculation was obtained by the ratio of the higher systolic pressure of the lower limb (dorsal of the foot or posterior tibial) right and left, in relation to the higher systolic pressure obtained in one of the upper limbs. For analysis and classification of $A B I$, the individuals were classified as normal $A B I$ from 1.0 to 1.4 , borderline from 0.90 to 0.99 , PAD $<0.90$ and arterial stiffness $>1.40$. 


\section{Familiarization test and 6-minute walk test}

The presence of intermittent claudication was determined by the familiarization test recommended by TASC $\|,{ }^{18}$ performed on a Caloi CLE 30 Premium model treadmill, with a speed of $3.2 \mathrm{~km} / \mathrm{h}$ and an incline of $10 \%$, lasting up to 5 minutes. It was possible to determine the initial claudication distance (ICD), pain-free walking time (PFWT), maximum walking distance (MWD) and maximum walking time (MWT) of the volunteers.

Functional capacity was measured by the 6-minute walk test (6MWT), adapted in a $15 \mathrm{~m}$ corridor. The individuals were classified according to the number of meters covered in 6 minutes as follows: level I = <300 m; level II = $300-374.9 \mathrm{~m}$; level III = $375-449.9 \mathrm{~m}$; level IV $=\geq 450 \mathrm{~m}$.

\section{Statistical analysis}

For data analysis, the Kolmogorov-Smirnov and Shapiro-Wilk sample normality tests were applied. The prevalence of PAD was estimated with the respective $95 \% \mathrm{Cl}$. The mean and standard deviation were used to analyze the variables age, education and BMI, in addition to the use of the non-parametric MannWhitney test in the variables age, weight, height, $\mathrm{HR}$ at rest, $\mathrm{SBP}, \mathrm{DBP}$ and $\mathrm{BMI}$ in the two groups (normal $\mathrm{ABI}$ and altered $A B I$ ), considering $p<0.01$ as a statistically significant value. The odds ratio (OR) was used in the variables sex, family history, $\mathrm{SAH}$, dyslipidemia, smoking, drinking, sedentary lifestyle, overweight and/ or obesity. All analyses were performed using the Stata Program, version 12.0.

\section{Results}

Selected for the study were one hundred and three participants at two FHS in Pindamonhangaba. Fortyeight volunteers declined the invitation due to difficulty in getting to the health unit or lack of time, and 17 were excluded for not meeting the inclusion criteria.

The study was carried out with 38 patients between 42 and 77 years old, with a mean age of $61.1 \pm 8.2$ (SD) years, of which $18.4 \%$ were over 70 . Table 1 shows the data on the sociodemographic profile of the 38 volunteers to characterize the study population.
Table 1 - Sociodemographic data of the study population $(n=38)$

\begin{tabular}{|c|c|c|}
\hline Sociodemographic data & $\mathbf{n}$ & $\%$ \\
\hline \multicolumn{3}{|l|}{ Age (years) } \\
\hline $40-49$ & 2 & 5.26 \\
\hline $50-59$ & 16 & 42.1 \\
\hline $60-69$ & 13 & 34.2 \\
\hline $70-79$ & 7 & 18.4 \\
\hline \multicolumn{3}{|l|}{ Sex } \\
\hline Female & 29 & 76.3 \\
\hline Male & 9 & 23.7 \\
\hline \multicolumn{3}{|l|}{ Time with DM (years) } \\
\hline$<10$ & 15 & 39.5 \\
\hline $10-20$ & 17 & 44.7 \\
\hline$>20$ & 6 & 15.8 \\
\hline \multicolumn{3}{|l|}{ Race } \\
\hline White & 20 & 52.6 \\
\hline Brown & 7 & 18.4 \\
\hline Black & 11 & 28.9 \\
\hline \multicolumn{3}{|l|}{ Schooling (years) } \\
\hline Illiterate & 3 & 7.9 \\
\hline $1-4$ & 15 & 39.5 \\
\hline $5-8$ & 12 & 31.6 \\
\hline $9-13$ & 8 & 21.0 \\
\hline \multicolumn{3}{|l|}{ Retired } \\
\hline Yes & 20 & 52.6 \\
\hline No & 18 & 47.4 \\
\hline
\end{tabular}

Note: $\mathrm{DM}=$ diabetes mellitus.

Regarding the $A B I$ values, $31.6 \%$ had some type of alteration. There was a prevalence of $21.1 \%$ of individuals with PAD (95\% $\mathrm{Cl}: 16.9$ to 25.8 ), this value being classified as mild PAD (15.8\%) and moderate PAD (5.3\%), while $10.5 \%$ of individuals had an $A B I$ over 1.4 , suggesting Mockenberg calcification.

There was no statistical difference in the variables compared between the groups of individuals with normal $A B I$ of 0.9 to 1.4 and altered $A B I$ of less than 0.9 or greater than 1.4, as seen in Table 2.

The mean BMI was $29.9 \mathrm{~kg} / \mathrm{m}^{2} \pm 5.9$, ranging from 20.6 to $42.3 \mathrm{~kg} / \mathrm{m}^{2}$, where $50 \%$ had a BMI greater than $30.0 \mathrm{~kg} / \mathrm{m}^{2}$ and were classified as obese. Through WC, a high risk of developing CVD was observed in females (93.1\%) and males (55.6\%) (Figure 1). 
Table 2 - Clinical characteristics of patients with diabetes compared by Mann-Whitney test

\begin{tabular}{lcccc}
\hline Parameters & Total $(\mathbf{n}=\mathbf{3 8})$ & Normal ABI $(\mathbf{n}=\mathbf{3 0})$ & Altered ABI $(\mathbf{n}=\mathbf{8})$ & p-valor \\
\hline Age $($ years $)$ & $61.1 \pm 8.2$ & $59.9 \pm 8.3$ & $63.8 \pm 8.2$ & 0.28 \\
Weight $(\mathrm{kg})$ & $78.0 \pm 14.4$ & $79.1 \pm 14.6$ & $73.5 \pm 16.8$ & 0.39 \\
Height $(\mathrm{cm})$ & $160.7 \pm 7.9$ & $160.8 \pm 7.7$ & $157.5 \pm 9.0$ & 0.48 \\
HRrest $(\mathrm{bpm})$ & $76.0 \pm 13.5$ & $74.4 \pm 11.7$ & $81.2 \pm 20.7$ & 0.53 \\
SAP $(\mathrm{mmHg})$ & $140.2 \pm 23.5$ & $141.9 \pm 24.6$ & $142.5 \pm 23.1$ & 0.95 \\
DAP $(\mathrm{mmHg})$ & $82.6 \pm 12.0$ & $84.2 \pm 12.3$ & $81.2 \pm 12.4$ & 0.56 \\
DP & $10703.9 \pm 2616.0$ & $10644.2 \pm 2533.7$ & $11498.7 \pm 3348.2$ & 0.85 \\
BMI $\left(\mathrm{kg} / \mathrm{m}^{2}\right)$ & $29.9 \pm 5.9$ & $30.7 \pm 6.2$ & $28.5 \pm 5.7$ & 0.39 \\
WC $(\mathrm{cm})$ & $103.9 \pm 11.5$ & $104.8 \pm 12.3$ & $101.2 \pm 8.5$ & 0.48 \\
\hline
\end{tabular}

Note: $A B I=$ ankle-brachial index; $H$ Rrest $=$ Heart rate at rest; $S A P=$ systolic arterial pressure; $D A P=$ diastolic arterial pressure; $D P=$ double product; $\mathrm{BMI}=$ body mass index $; \mathrm{WC}=$ waist circumference .

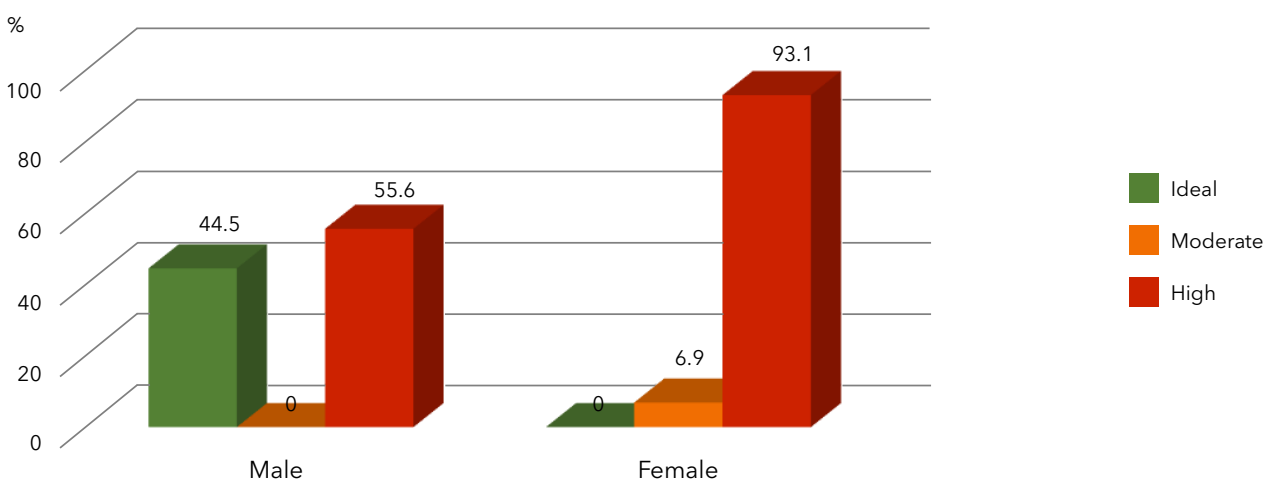

Figure 1 - Cardiovascular risk between sexes measured by waist circumference.

Table 3 shows the more prevalent risk factors in individuals with altered and normal ABI. Table 4 presents the OR for the variables: sex, $0.724(0.578-0.907)$, family history: 0.333 (0.059-1.868), SAH: $0.758(0.625-0.919)$, dyslipidemia: 0.525 (0.106 - 2.603), smoking current and/or past: $2.727(0.542$ - 13,726), drinking current and/or past: 0.929 (0.089 - 9.687), physical inactivity: 0.778 (0.070 - 8.669) and overweight and/or obesity: $0.778(0.131-4.615)$, where there was a greater chance of developing PAD among smokers and/or ex-smokers.

In individuals with $\mathrm{ABI}$ at normal values, the 6MWT showed a higher percentage with functional capacity at level III according to the classification of the Studies of Left Ventricular Dysfunction (SOLVD), which means performance from 375 to $449.9 \mathrm{~m}$, representing $42.3 \%$ of individuals. The functional capacity of volunteers with $\mathrm{ABI}$ in altered values was mostly classified as level I (50\%), followed by level II (25\%) and level IV (25\%).

The familiarization test was applied to 38 volunteers. Of the individuals with normal ABI, 11 (28.9\%) had symptoms in the calves, and the following results were obtained: mean PFWT of 1:40 minutes, mean DIC of $77.3 \pm 66.19 \mathrm{~m}$, mean MDC of $152.7 \pm 100.7 \mathrm{~m}$, and mean TMC of 3:10 minutes.

Regarding individuals with altered $A B I, 21.1 \%$ had PFWT with a mean of 00:44 seconds, DIC with a mean of $33.7 \pm 39.25 \mathrm{~m}, \mathrm{MDC}$ with a mean of $156.8 \pm 108.39 \mathrm{~m}$ and TMC with a mean of 3:12 minutes. 
Table 3 - Prevalent risk factors of PAD in the sample $(n=38)$

\begin{tabular}{|c|c|c|c|c|}
\hline \multirow{2}{*}{ Parameters } & \multicolumn{2}{|c|}{ Normal ABI } & \multicolumn{2}{|c|}{ Abnormal ABI } \\
\hline & $\mathbf{n}$ & $\%$ & $\mathbf{n}$ & $\%$ \\
\hline \multicolumn{5}{|l|}{ Sex } \\
\hline Female & 21 & 69.2 & 8 & 100.0 \\
\hline Male & 9 & 30.7 & - & - \\
\hline \multicolumn{5}{|l|}{ Race } \\
\hline White & 2 & 7.7 & - & - \\
\hline Brown & 23 & 76.9 & 6 & 75.0 \\
\hline Black & 5 & 15.4 & 2 & 25.0 \\
\hline \multicolumn{5}{|l|}{ BMI } \\
\hline Normal weight & 9 & 30.0 & 2 & 25.0 \\
\hline Overweight & 4 & 13.33 & 4 & 50.0 \\
\hline Obesity grade I & 9 & 30.0 & - & - \\
\hline Obesity grade II & 6 & 20.0 & 2 & 25.0 \\
\hline Obesity grade III & 2 & 6.67 & - & - \\
\hline \multicolumn{5}{|c|}{ Time with DM (years) } \\
\hline$<10$ & 13 & 43.3 & 2 & 25.0 \\
\hline $10-20$ & 13 & 43.3 & 4 & 50.0 \\
\hline$>20$ & 4 & 13.4 & 2 & 25.0 \\
\hline \multicolumn{5}{|l|}{ Family history } \\
\hline Yes & 25 & 80.8 & 5 & 62.5 \\
\hline No & 5 & 19.2 & 3 & 37.5 \\
\hline \multicolumn{5}{|l|}{ SAH } \\
\hline Yes & 25 & 80.8 & 8 & 100.0 \\
\hline No & 5 & 19.2 & - & - \\
\hline \multicolumn{5}{|l|}{ Dyslipidemia } \\
\hline Yes & 16 & 53.8 & 3 & 37.5 \\
\hline No & 14 & 46.2 & 5 & 62.5 \\
\hline \multicolumn{5}{|l|}{ Smoking } \\
\hline Yes & 11 & 30.8 & 5 & 62.5 \\
\hline No & 19 & 69.2 & 3 & 37.5 \\
\hline \multicolumn{5}{|l|}{ Physical inactivity } \\
\hline Yes & 27 & 92.3 & 7 & 87.5 \\
\hline No & 3 & 7.7 & 1 & 12.5 \\
\hline \multicolumn{5}{|l|}{ Drinking } \\
\hline Yes & 4 & 13.3 & 1 & 12.5 \\
\hline Noo & 26 & 86.7 & 7 & 87.5 \\
\hline
\end{tabular}

Note: $P A D=$ peripheral arterial disease $; A B I=$ ankle-brachial index; $\mathrm{BMI}=$ body mass index; $\mathrm{DM}=$ diabetes mellitus; $\mathrm{SAH}=$ systemic arterial hypertension.
Table 4 - Odds ratio (OR) of risk factors for PAD in individuals with DM2 $(n=38)$

\begin{tabular}{lcc}
\hline Parameters & OR & IC95\% \\
\hline Female sex & 0.724 & $0.578-0.907$ \\
Family history & 0.333 & $0.059-1.868$ \\
SAH & 0.758 & $0.625-0.919$ \\
Dyslipidemia & 0.525 & $0.106-2.603$ \\
Smoking & 2.727 & $0.542-13.726$ \\
Drinking & 0.929 & $0.089-9.687$ \\
Physical inactivity & 0.778 & $0.070-8.669$ \\
Overweight/obesity & 0.788 & $0.131-4.615$ \\
\hline
\end{tabular}

Note: $P A D=$ peripheral arterial disease; $D M 2$ = type 2 diabetes mellitus; $\mathrm{Cl}=$ confidence interval; $\mathrm{HAS}=$ systemic arterial hypertension .

\section{Discussion}

This study showed the prevalence of PAD associated with risk factors in the population with DM2 in the city of Pindamonhangaba, SP. This is the first study on the prevalence of PAD in patients with DM2 carried out in this city.

The estimated prevalence of PAD varies according to the characteristics of the study population, the criteria used for diagnosis and age group. In this study, there was a prevalence of $21.1 \%(95 \% \mathrm{Cl}: 16.9-25.8)$ of PAD in individuals with $D M 2$, based on $A B 1$.

In determining the prevalence of $P A D$, there is a high dependence on the diagnostic method. Most studies use a low ABI ( $\leq 0.90)$, which is significant for PAD. Soyoye et al. ${ }^{19}$ and Mwebaze et al. ${ }^{20}$ estimated the prevalence of PAD in individuals with diabetes using three methods: symptomatology of intermittent claudication (IC), palpation of the arteries and $A B I$ assessment. These authors showed higher percentages of PAD detection with $A B I$ measurement and obtained a prevalence close to that found in the present study. Thus, the $A B I$ diagnostic method has great diagnostic sensitivity and specificity for PAD.

Some studies have reported prevalence rates of PAD in diabetic patients similar to those found in our study. Okello et al. ${ }^{21}$ found a prevalence of PAD in $24 \%$ of participants with a mean age of 60 years, similar to that observed in the present study (61.1 years), and both studies included predominantly females. 
The prevalence of PAD increases with age, and epidemiological studies have found that this varies from 3 to $10 \%$ in individuals younger than 70 years old and from 15 to $20 \%$ in those over $70 .^{4}$

Using $A B I$ to diagnose PAD, Lange et al. ${ }^{22}$ observed a prevalence of PAD of $26.3 \%$ in patients with type I and type II diabetes, while in non-diabetic patients, prevalence was lower (15.3\%).

Shukla et al., ${ }^{23}$ in a university hospital in India, also found using $A B I$ a prevalence of $36 \%$ for PAD in patients with DM2. The investigators observed a correlation of prevalence with time from diagnosis of diabetes, WC, diagnosis of $\mathrm{SAH}$, and microvascular complications caused by chronic hyperglycemia, a condition that makes screening for PAD important in all individuals with diabetes.

The study of Akalu, ${ }^{24}$ in which color Doppler was used, found a PAD prevalence of $30.7 \%$ in DM2 patients. In agreement with that study, Hur et al. ${ }^{25}$ found a prevalence of $28.7 \%$ for this condition in individuals with $\mathrm{DM} 2$, also using the $\mathrm{ABI}$ diagnostic method, but only $17.2 \%$ of them had abnormal $A B I$. This finding is mainly explained by the diagnostic method used, as it suggests that $A B I$ underestimates the presence of $P A D$ in these patients. In the latter, ${ }^{25}$ it was found that $23 \%$ of individuals with normal $A B I$ showed some degree of PAD by color Doppler.

When analyzing the sex of the study samples, ${ }^{20,21,26,27}$ there is a predominance of females, as seen in the present investigation. This could be explained by the fact that women take better care of themselves and their family, where they tend to seek health services more often and earlier when symptoms arise throughout life, showing a greater number of supported women than men. ${ }^{28}$

Regarding race, there was a higher prevalence of DM2 in whites. The term race is related to self-reported skin color, but in some studies the term ethnicity is used, which goes beyond physical characteristics, thus cultural, social, linguistic, religious, place of origin and dietary issues. ${ }^{29}$ Both are closely related in the identification of socioeconomic disparities and exposure to health risks, ${ }^{30}$ but there are questions regarding the use of race and ethnicity in research due to heterogeneity and methodological complexity in the use of these variables. ${ }^{31,32}$

DM2 is closely associated with obesity, ${ }^{33-35}$ and individuals with DM2 are at higher risk of developing CVD. ${ }^{34}$ Daousi et al. ${ }^{35}$ demonstrated that most patients with DM2 are overweight (34\%) or obese (60.1\%), as also seen here and in other studies, ${ }^{19-22,26,36}$ which obtained high percentages of their population with a higher than ideal BMI.

In individuals with PAD, the cumulative effect of risk factors directly influences the increase in the prevalence of the disease, according to the study by Eraso et al., ${ }^{37}$ which found that the highest prevalence was among elderly, blacks and non-Hispanic women. In addition, the probability is increased according to the association of each risk factor, reaching more than ten times with the combination of three or more risk factors such as sex, race, SAH, DM, chronic kidney disease and smoking. In the study by Alvim et al., ${ }^{38}$ in the general population investigated, the prevalence of PAD was low, but it increased with age, and the risk factors for this disease were mainly smoking, sedentary lifestyle, diabetes and age.

In the present study, it was observed that in the population with DM2 and altered $A B I$, there was the presence of more than three risk factors. In addition, all individuals were female, older than 50 years, overweight or obese in the majority (75\%), all had $\mathrm{SAH}$, and $62.5 \%$ were smokers.

A study carried out in Sri Lanka found that individuals with PAD, when compared to the control group, had a significantly higher proportion of history of DM, SAH, dyslipidemia and smoking. ${ }^{39}$ In the sample of this study, higher percentages were found in the PAD group for factors such as SAH and smoking compared to the diabetes group without PAD.

The patient diagnosed with diabetes has clinical characteristics different from individuals without diabetes when compared to histological characteristics. Occlusive disease occurs in a generalized way, mainly distally, making the appearance of arterial calcification frequent and providing greater occlusion than stenosis of the arteries. ${ }^{40}$

In the present study, diabetics with and without PAD had similar percentages among some risk factors. This was also found in the studies by Lange et al.,22 Narayanan et al., ${ }^{26}$ and Agarwal et al., ${ }^{41}$ such as mean age, $\mathrm{SAH}$, smoking, overweight and/or obesity. Diabetes is one of the strongest factors for the development of symptomatic and asymptomatic PAD, and its complications favor an increased risk of cardiovascular events and mortality. ${ }^{42-44}$ The process of atherosclerosis in patients with diabetes is more accentuated. ${ }^{44}$ 
Smoking is another modifiable and important risk factor for the development and progression of PAD, acting on endothelial dysfunction, changes in lipid metabolism and the coagulation process. ${ }^{42,43}$ In the present study, high percentages of current and/or past history of smoking were observed in diabetic individuals with altered $A B I$, while in those with normal $A B I$ the percentage was lower. Narayanan et al. ${ }^{26}$ and Akram et al. ${ }^{27}$ found a slight difference between the percentages of current and/or past smoking in individuals with altered ABI. In the study by Tavintharan et al., ${ }^{45}$ there was a prevalence of PAD in $10.4 \%$ of individuals with diabetes and with high percentages in relation to smoking, showing a strong association with PAD in these individuals.

SAH may be present in patients diagnosed with diabetes and PAD, as it represents an important cardiovascular risk factor. In combination, they increase the risk of fatal cardiovascular events, as it is possible to see high percentages of hypertensive patients in both groups. ${ }^{46}$ Similar percentages were also found between groups by Narayanan et al., ${ }^{26}$ in which SAH was found in $72.2 \%$ of individuals with PAD and $61.1 \%$ of individuals without PAD. Agarwal et al. ${ }^{41}$ observed that $93.9 \%$ of individuals with PAD and $85.2 \%$ without PAD had SAH, corroborating the results reported in this study.

Dyslipidemia is another risk factor for the development of various cardiovascular pathologies. ${ }^{47}$ Here, we found higher percentages of dyslipidemia in individuals diagnosed with diabetes without PAD. Likewise, Alzahrani et al. ${ }^{48}$ did not find an association between dyslipidemia and a higher prevalence of PAD.

None of the analyzed studies ${ }^{19-21,22,26,46}$ found sedentary lifestyle to be a risk factor for PAD. In this study, percentages were slightly higher in individuals with diabetes without PAD compared to those with PAD. However, Makdisse et al. ${ }^{49}$ observed a higher prevalence of PAD in individuals who did not engage in physical activity.

In a study carried out in San Diego, in the U.S., Criqui et al. ${ }^{50}$ sought to identify the prevalence of PAD according to race and found that blacks had a higher prevalence, followed by non-Hispanic whites. This percentage difference between whites and blacks was not verified in the present study.

Obesity is also reported as a considerable risk factor for PAD. Huang et al. ${ }^{51}$ observed for each $1 \mathrm{~kg} /$ $\mathrm{m}^{2}$ increase in BMI a 1.06-fold risk of developing PAD.
Likewise, we observed that individuals with PAD were obese or overweight.

Cardiovascular risk can be measured through BMI, WC and waist-hip ratio (WHR). Mohammadifard et al. ${ }^{52}$ evaluated the association between $\mathrm{BMI}$ and $\mathrm{WC}$, relating it to cardio-metabolic risk factors, and they found that the occurrence of DM2, SAH and dyslipidemia was significantly associated with an increase in indicators of obesity. In the population studied, it was found that $50 \%$ had a BMI greater than $30 \mathrm{~kg} / \mathrm{m}^{2}$ and more than $90 \%$ of women had WC above normal values, indicating that these patients show important indicators of cardiovascular risk, in addition to diabetes, regardless of the presence or absence of PAD.

Individuals diagnosed with asymptomatic PAD have greater functional impairment and early decline in the level of activity than individuals without PAD, showing a range of symptoms in the lower limbs that cause functional limitation. ${ }^{53}$ Individuals diagnosed with diabetes have impaired functional capacity at a submaximal and maximal level, regardless of the effects of obesity. In addition, this reduced functional capacity is present even without cardiovascular compromise. ${ }^{54,55}$ According to a survey by Anjos et al., ${ }^{56}$ patients with DM have a shorter distance walked in the 6MWT compared with individuals without DM. In accordance, Gregg et al. ${ }^{57}$ estimated the prevalence of functional disability in 60-year-old Americans with diabetes, who had greater difficulty in performing activities when compared to individuals without diabetes.

Anderson et al. ${ }^{58}$ related the functional capacity of individuals with PAD and obtained results similar to our findings, which showed a mean distance of $296.2 \mathrm{~m}$ covered by volunteers with altered $A B I$ in the $6 \mathrm{MWT}$. The result obtained shows that individuals with PAD have low functional capacity.

It is observed that both groups, with normal $A B \mid$ and altered $A B I$, had low functional capacity, being predominant in the group with altered ABI. Likewise, Scherer et al..$^{59}$ showed little difference between the group with altered $A B I$ and the control group, and Gomes et al. ${ }^{60}$ observed that individuals with $A B I$ less than 0.9 had a shorter distance walked in meters when compared to individuals with normal $A B I$.

Intermittent claudication may be present in individuals with PAD and is related to a decreased ability to walk when compared to the healthy population. Scherer et al. ${ }^{59}$ observed that the mean distance covered 
by individuals with altered $A B I$ in the $6 \mathrm{MWT}$ was $385 \mathrm{~m}$, being lower than that found in the control group, with a difference of $94.1 \mathrm{~m}$. In the present study, individuals with altered $A B I$ had lower capacity $(296 \mathrm{~m})$, followed by individuals with borderline (342 m) and normal (378 m) ABI.

The symptomology of intermittent claudication also directly interferes with functional capacity. Here, we found that the individuals presented with symptoms with a mean of $33.7 \mathrm{~m}$ walked, and these individuals walked a mean of $156.8 \mathrm{~m}$ even with the symptoms. This was different than that found by Scherer et al., ${ }^{59}$ in which the subjects studied showed symptomology with a mean of $158.6 \mathrm{~m}$ and walked about $385 \mathrm{~m}$.

Anderson et al. ${ }^{58}$ observed a claudication time of 222 seconds and a maximum walk time of 505 seconds. In the present study, however, there was a short time of claudication onset ( 44 seconds) and maximum walk time of 187 seconds.

\section{Conclusion}

The present study, carried out in individuals diagnosed with DM2 with and without PAD and users of FHS in the city of Pindamonhangaba, SP, allowed us to conclude that the prevalence of PAD reached more than a fifth of individuals with DM2, and the most common characteristics in this population were overweight, $\mathrm{SAH}$, smoking, sedentary lifestyle, the age group between 51 and 69 years and females. It can also be observed that all individuals with abnormal $A B I$ were females, and that $\mathrm{SAH}$ and smoking were the risk factors most present in this population. With regard to functional capacity, there was a decrease in functional capacity according to the 6MWT in both groups, being greater in the group with altered $\mathrm{ABI}$.

\section{Authors' contributions}

All authors were responsible for the conception and design of the study. PJSF and VCRM were responsible for the data acquisition, and PJSF for the analysis and interpreation of the data. He also wrote the article, while VCRM, ECMT and ECAPSP revised it critically for important intellectual content. All authors aproved the final version.

\section{References}

1. Mohammedi K, Woodward M, Hirakawa Y, Zoungas S, Williams $B$, Lisheng $L$, et al. Microvascular and macrovascular disease and risk for major peripheral arterial disease in patients with type 2 diabetes. Diabetes Care. 2016;39(10):1796-803. DOI

2. Criqui $\mathrm{MH}$, Aboyans V. Epidemiology of peripheral artery disease. Circ Res. 2015;116(9):1509-26. DOI

3. Yeboah K, Puplampu P,Ainuson J,Akpalu J, Gyan B,Amoah AGB. Peripheral artery disease and exertional leg symptoms in diabetes patients in Ghana. BMC Cardiovasc Disord. 2016;16:68. DOI

4. Aboyans V, Ricco JB, Bartelink MLEL, Björck M, Brodmann M, Cohnert T, et al. 2017 ESC Guidelines on the Diagnosis and Treatment of Peripheral Arterial iseases in collaboration with the European Society for Vascular Surgery (ESVS). Eur Heart J. 2018;39(9):763-816. DOI

5. Katakami N. Mechanism of development of atherosclerosis and cardiovascular disease in diabetes mellitus. J Atheroscler Thromb. 2018;25(1):27-39. DOI

6. Singh R, Devi S, Gollen R. Role of free radical in atherosclerosis, diabetes and dyslipidaemia: larger-than-life. Diabetes Metab Res Rev. 2015;31(2):113-26. DOI

7. Matsuda M, Shimomura I. Increased oxidative stress in obesity: implications for metabolic syndrome, diabetes, hypertension, dyslipidemia, atherosclerosis, and cancer. Obes Res Clin Pract. 2013;7(5):e330-41. DOI

8. Li H, Horke S, Förstermann U. Vascular oxidative stress, nitric oxide and atherosclerosis. Atherosclerosis. 2014;237(1):208-19. $\mathrm{DOI}$

9. Zeadin MG, Petlura Cl, Werstuck GH. Molecular mechanisms linking diabetes to the accelerated development of atherosclerosis. Can J Diabetes. 2013;37(5):345-50. DOI

10. Lankin VZ, Tikhaze AK. Role of oxidative stress in the genesis of atherosclerosis and diabetes mellitus: a personal look back on 50 years of research. Curr Aging Sci. 2017;10(1):18-25. DOI

11. Castro I, Fontana Filho H. Characteristics and adverse events in acute coronary syndrome patients with a history of peripheral arterial disease. Arq Bras Cardiol. 2019;113(3):373. DOI 
12. Mascarenhas JV, Albayati MA, Shearman CP, Jude EB. Peripheral arterial disease. Endocrinol Metab Clin North Am. 2014;43(1):149-66. DOI

13. Gibbs BB, Dobrosielski DA, Althouse AD, Stewart KJ. The effect of exercise trainingon ankle-brachial index in type 2 diabetes. Atherosclerosis. 2013;230(1):125-30. DOI

14. Naldi L, Bernetti M, Baroni F, Boddi M. Ankle-brachial index: which clinical use? G Ital Cardiol (Rome). 2015;16(12):681-9. DOI

15. Bianchi C, Penno G, Pancani F, Civitelli A, Piaggesi A, Caricato $F$, et al. Non-traditional cardiovascular risk factors contribute to peripheral arterial disease in patients with type 2 diabetes. Diabetes Res Clin Pract. 2007;78(2):246-53. DOI

16. Associação Brasileira para o Estudo da Obesidade e da Síndrome Metabólica. Diretrizes Brasileiras de Obesidade 2009/2010. 4 ed. São Paulo: ABESO; 2016. Full text link

17. Lean ME, Han TS, Morrison CE. Waist circumference as a measure for indicating need for weight management. BMJ. 1995;311(6998):158. DO।

18. Norgren L, Hiatt WR, Dormandy JA, Nehler MR, Harris KA, Fowkes FGR, et al. Inter-Society Consensus For The Management Of Peripheral Arterial Disease (TASC II). Eur J Vasc Endovasc Surg. 2007;33(Suppl 1):S1-75. DOI

19. Soyoye DO, Ikem RT, Kolawole BA, Oluwadiya KS, Bolarinwa RA, Adebayo OJ. Prevalence and correlates of peripheral arterial disease in Nigerians with type 2 diabetes. Adv Med. 2016;2016:3529419. DOI

20. Mwebaze RM, Kibirige D. Peripheral arterial disease among adult diabetic patients attending a large outpatient diabetic clinic at a national referral hospital in Uganda: a descriptive cross sectional study. PLoS One. 2014;9(8):e105211. DOI

21. Okello S, Millard A, Owori R, Asiimwe SB, Siedner MJ, Rwebembera J, et al. Prevalence of lower extremity peripheral artery disease among adult diabetes patients in southwestern Uganda. BMC Cardiovasc Disord. 2014;14:75. DOI

22. Lange S, Diehm C, Darius H, Haberl R, Allenberg JR, Pittrow $D$, et al. High prevalence of peripheral arterial disease and low treatment rates in elderly primary care patients with diabetes. Exp Clin Endocrinol Diabetes. 2004;112(10):566-73. DOI
23. Shukla V, Fatima J, Ali M, Garg A. A study of prevalence of peripheral arterial disease in type 2 diabetes mellitus patients in a teaching hospital. J Assoc Physicians India. 2018;66(5):5760. PubMed

24. Akalu $Y$, Birhan A. Peripheral arterial disease and its associated factors among type 2 diabetes mellitus patients at Debre Tabor General Hospital, Northwest Ethiopia. J Diabetes Res. 2020;2020:9419413. DOI

25. Hur KY, Jun JE, Choi YJ, Lee Y, Kim DJ, Park SW, et al. Color doppler ultrasonography is a useful tool for diagnosis of peripheral artery disease in type 2 diabetes mellitus patients with ankle-brachial index 0.91 to 1.40. Diabetes Metab J. 2018;42(1):63-73. DOI

26. Narayanan RML, Koh WP, Phang J, Subramaniam T. Peripheral arterial disease in community-based patients with diabetes in Singapore: results from a primary healthcare study. Ann Acad Med Singap. 2010;39(7):525-31. Full text link

27. Akram J, Aamir AU, Basit A, Qureshi MS, Mehmood T, Shahid SK, et al. Prevalence of peripheral arterial disease in type 2 diabetics in Pakistan. J Pak Med Assoc. 2011;61(7):644-8. Full text link

28. Carolino IDR, Molena-Fernandes CA, Tasca RS, Marcon SS, Cuman RKN. Fatores de risco em pacientes com diabetes mellitus tipo 2. Rev Latino-Am Enfermagem. 2008;16(2):1-7. DO।

29. Moretto MC, Fontaine AM, Garcia CAMS, Neri AL, Guariento ME. Associação entre cor/raça, obesidade e diabetes em idosos da comunidade: dados do Estudo FIBRA. Cad Saude Publica. 2016;32(10):e00081315. DOI

30. Alves C, Fortuna CMM, Toralles MBP. A aplicação e o conceito de raça em saúde pública: definições, controvérsias e sugestões para uniformizar sua utilização nas pesquisas biomédicas e na prática clínica. Gaz Med Bahia. 2005;75(1):92115. Full text link

31. Laguardia J. O uso da variável "raça" na pesquisa em saúde. Physis. 2004;14(2):197-234. DOI

32. Golden SH, Yajnik C, Phatak S, Hanson RL, Knowler WC. Racial/ethnic differences in the burden of type 2 diabetes over the life course: a focus on the USA and India. Diabetologia. 2019;62(10):1751-60. DO| 
33. Davies M, Khunti K. Insulin management in overweight or obese type 2 diabetes patients: the role of insulin glargine. Diabetes Obes Metab. 2008;10(Suppl 2):42-9. DOI

34. Wilding JPH. The importance of weight management in type 2 diabetes mellitus. Int J Clin Pract. 2014;68(6):682-91. DOI

35. Daousi C, Casson IF, Gill GV, MacFarlane IA, Wilding JPH, Pinkney JH. Prevalence of obesity in type 2 diabetes in secondary care: association with cardiovascular risk factors. Postgrad Med J. 2006;82(966):280-4. DOI

36. Oliveira JE, Milech A, Franco LJ. The prevalence of diabetes in Rio de Janeiro, Brazil. Diabetes Care. 1996;19(6):663-6. DOI

37. Eraso LH, Fukaya E, Mohler ER, Xie D, Sha D, Berger JS. Peripheral arterial disease, prevalence and cumulative risk factor profile analysis. Eur J Prev Cardiol. 2014;21(6):704-11. DOI

38. Alvim RO, Dias FAL, Oliveira CM, Vançan AR, Horimoto $R$, Ulbrich $A Z$, et al. Prevalência de doença arterial periférica e fatores de risco associados em uma população rural brasileira: estudo corações de Baependi. Int J Cardiovasc Sci. 2018;31(4):405-13. Full text link

39. Weragoda J, Seneviratne R, Weerasinghe MC, Wijeyaratne SM. Risk factors of peripheral arterial disease: a case control study in Sri Lanka. BMC Res Notes. 2016;9(1):508. DOI

40. Faglia E. Characteristics of peripheral arterial disease and its relevance to the diabetic population. Int J Low Extrem Wounds. 2011;10(3):152-66. DO।

41. Agarwal AK, Singh $M$, Arya $V$, Garg $U$, Singh VP, Jain $V$. Prevalence of peripheral arterial disease in type 2 diabetes mellitus and its correlation with coronary artery disease and its risk factors. J Assoc Physicians India. 2012;60:28-32. PubMed

42. Olin JW, Sealove BA. Peripheral artery disease: current insight into the disease and its diagnosis and management. Mayo Clin Proc. 2010;85(7):678-92. DOI

43. Shammas NW. Epidemiology, classification and modifiable risk factors of peripheral arterial disease. Vasc Health Risk Manag. 2007;3(2):229-34. Full text link

44. Marso SP, Hiatt WR. Peripheral arterial disease in patients with diabetes. J Am Coll Cardiol. 2006;47(5):921-9. DOI
45. Tavintharan S, Cheung N, Lim SC, Tay W, Shankar A, Tai ES, et al. Prevalence and risk factors for peripheral artery disease in an Asian population with diabetes mellitus. Diab Vasc Dis Res. 2009;6(2):80-6. DOI

46.Criqui MH, Langer RD, Fronek A, Feigelson HS, Klauber MR, McCann TJ, et al. Mortality over a period of 10 years in patients with peripheral arterial disease. N Engl J Med. 1992;326(6):3816. DOI

47. Yusuf S, Hawken S, Ounpuu S, Dans T, Avezum A, Lanas F, et al. Effect of potentially modifiable risk factors associated with $\mathrm{MI}$ in 52 countries (the INTERHEART study): case-control study. Lancet. 2004;364(9438):937-52. DOI

48. Alzahrani HA, Wang D, Bakhotmah BA, Hu FB. Risk factors for peripheral artery disease among patients with diabetes in Saudi Arabia. Vasc Med. 2014;19(2):103-11. DOI

49. Makdisse M, Pereira AC, Brasil DP, Borges JL, MachadoCoelho GLL, Krieger JE, et al. Prevalência e fatores de risco associados à doença arterial periférica no projeto corações do Brasil. Arq Bras Cardiol. 2008;91(6):402-14. DOI

50. Criqui $\mathrm{MH}$, Vargas $\mathrm{V}$, Denenberg JO, Ho $\mathrm{E}$, Allison $\mathrm{M}$, Langer RD, et al. Ethnicity and peripheral arterial disease: the San Diego population study. Circulation. 2005;112(17):27037. DOI

51. Huang $Y, X u M, X i e ~ L$, Wang $T$, Huang $X$, Lv $X$, et al. Obesity and peripheral arterial disease: a mendelian randomization analysis. Atherosclerosis. 2016;247:218-24. DOI

52. Mohammadifard N, Nazem M, Sarrafzadegan N, Nouri F, Sajjadi F, Maghroun $M$, et al. Body mass index, waistcircumference and cardiovascular disease risk factors in Iranian adults: Isfahan Healthy Heart Program. J Health Popul Nutr. 2013;31(3):388-97. DOI

53. McDermott MM, Greenland P, Liu K, Guralnik JM, Criqui MH, Dolan NC, et al. Leg symptoms in peripheral arterial disease: associated clinical characteristics and functional impairment. JAMA. 2001;286(13):1599-606. DOI

54. Schneider SH, Amorosa LF, Khachadurian AK, Ruderman NB. Studies on the mechanism of improved glucose control during regular exercise in type 2 (non-insulindependent) diabetes. Diabetologia. 1984;26(5):355-60. DOI 
55. Reusch JEB, Bridenstine M, Regensteiner JG. Type 2 diabetes mellitus and exercise impairment. Rev Endocr Metab Disord. 2013;14(1):77-86. DOI

56. Anjos DMC, Araújo IL, Barros VM, Pereira DAG, Pereira DS. Avaliação da capacidade funcionalem idosos diabéticos. Fisioter Pesqui. 2012;19(1):73-8. DOI

57. Gregg EW, Beckles GL, Williamson DF, Leveille SG, Langlois JA, Engelgau MM, et al. Diabetes and physical disability among older U.S. adults. Diabetes Care. 2000;23(9):1272-7. DOI

58. Anderson JD, Epstein FH, Meyer $\mathrm{CH}$, Hagspiel KD, Wang $\mathrm{H}$, Berr SS, et al. Multifactorial determinants of functional capacity in peripheral arterial disease: uncoupling of calf muscle perfusion and metabolism. J Am Coll Cardiol. 2009;54(7):628-35. DOI
59. Scherer SA, Hiatt WR, Regensteiner JG. Lack of relationship between gait parameters and physical function in peripheral arterial disease. J Vasc Surg. 2006;44(4):782-8. DOI

60. Gomes TJN, Albuquerque IM, Costa PM, Cardoso DM, Costa GM, Vieira JLC. Association between the ankle-brachial index, intermittent claudication, and physical activity level: what is the influence on the functional capacity of patients with or at high risk of cardiovascular disease? Int J Gen Med. 2015;8:55-62. DOI 